\title{
Lanthanum Cation (3)
}

National Cancer Institute

\section{Source}

National Cancer Institute. Lanthanum Cation (3). NCI Thesaurus. Code C61802.

The ionized form of lanthanum (trivalent ion) with phosphate binding property.

Lanthanum ion binds dietary phosphate and inhibits the absorption of phosphate by

forming highly insoluble lanthanum-phosphate complexes that reduce the concentrations of serum phosphate and calcium phosphate. 